\title{
REVIEW
}

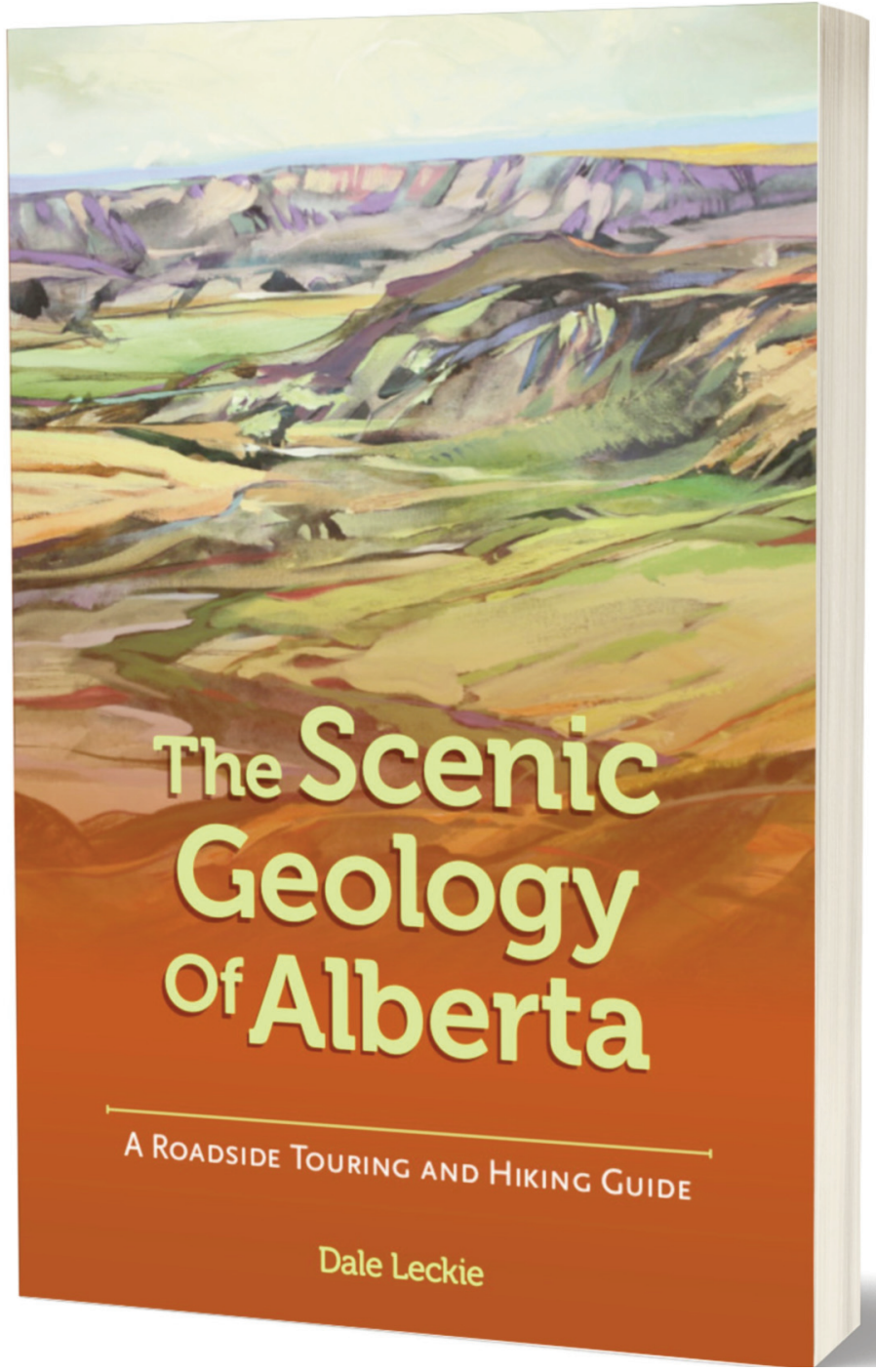

The Scenic Geology of Alberta: A Roadside Touring and Hiking Guide

\section{Dale Leckie}

Published by: Sandhill Book Marketing and Alpine Book Peddlers Published: 2021; 280 p.

Purchase price: $\$ 27.95$ (CND)

E-mail: leckied@shaw.ca

\author{
Reviewed by Stephen T. Johnston \\ University of Alberta \\ Department of Earth and Atmospheric Sciences \\ Edmonton, Alberta, T6G 2E3, Canada \\ E-mail:stjobnst@ualberta.ca
}

Many of us have signed up for and enjoyed geological field trips associated with Earth Science conferences. And the field trip guidebook is usually taken home - a treasured keepsake and a source of data and insights that often are unavailable elsewhere. In writing their guidebook, the trip leaders can assume that: 1) it is okay to use geological jargon (indeed, it is an expectation); 2) they have an interested audience (after all, we have already paid to come on the field trip); 3) geological maps and cross-sections will be (for the most part) readily understood by the field trip participants; and 4) everyone will happily pretend that they can grasp the concept of deep time. However, none of these assumptions are valid for the brave soul who pens a geological guidebook for a 'lay' audience, for the public. The immediate challenge in writing such a guidebook is to induce in people the idea that it might be fun (?) to purchase a field trip guidebook and to commit to spending time travelling around looking at and learning about rocks. This is the trick that Dale Leckie is attempting.

His first attempt, published in 2017, was "Rocks, Ridges and Rivers: Geological Wonders of Banff, Yoho, and Jasper National Parks. A Roadside Tour Guide" (a book which was favourably reviewed in these pages by Andy Kerr). I have a copy of that book. Indeed, I attended the Edmonton book release (at Audrey's Books - a wonderful place to get lost browsing for books) where I got to meet Dale. I purchased several copies of his book, and they have proven to be excellent gifts. And I have put my copy (signed by Dale) to good use, having had it along with me for hikes in and adjacent to Banff, Yoho, and Jasper parks.

But then, I am a geologist, not the audience that Dale was thinking about when he wrote Rocks, Ridges and Rivers. As Dale stated in the book's preface, his goal was to "share my curiosity for natural history", and to share it as broadly as possible. Toward that goal, he teamed up with an artist, Heather Pant, and filled the book with her artistic renderings of many of the scenic stops described in the book. This was Dale's stroke of brilliance! Geology isn't all science or just science. Most everyone recognizes the intrinsic beauty of the mountains and landscapes of Alberta. Heather's paintings provide implicit recognition of that beauty and allow Dale to then share widely the 
geological basis for that beauty. This is the recipe Dale has employed: 1) look at how beautiful this vista is, and now 2) listen to the incredible geological backstory to this vista.

Dale's recently published second book, "The Scenic Geology of Alberta: A roadside touring and hiking guide" (hereafter Scenic Alberta) follows the same recipe. It is targeted, just as was Rocks, Ridges and Rivers, at as broad an audience as possible. And instead of one artist, Dale has now teamed up with two (L.C. Cariou and Brent R. Laycock). It is Brent's work 'Landforms Coulee' that adorns the front cover and it sends a clear message - the foundation of this beautiful landscape is a wonderful geological story that spans millennia; come let me share that story with you. And sharing those stories is something that Dale is very good at.

Rocks, Ridges and Rivers focused on the geology in and immediately adjacent to Banff, Yoho, and Jasper national parks. This was low hanging fruit. These parks are home to some of the most beautiful and accessible mountains on Earth. Scenic Alberta is in many ways a more ambitious work in that Dale asks the reader to appreciate not just the mountains, but the far more subtle beauty and geology of the Prairies. Dale organizes about 80 (depending upon how you count them) 'geological stops' and hikes into 7 different 'subregions' including 1) Southern Alberta (including Waterton Park), 2) Calgary and Kananaskis area, 3) Red Deer River Valley, 4) Dinosaur Provincial Park, 5) Disruption in the Prairies, 6) Crossing Central Alberta, and 7) Checking out the North. In addition to the use of art to help convey the message, Scenic Alberta sticks with many of the same things that made Rocks, Rivers and Ridges a success: high-quality paper and binding (this is a guidebook that will last and which is ready for a bit of rain or snow); lots of excellent graphics and photographs; plenty of space for making annotations; a mixture of accessible and somewhat more adventuresome stops; a full stratigraphic column with notes printed on the inside of the front cover; and the use of sidebars to provide more information on select topics. It is an all-around excellent guidebook that could be the basis for several extended trips exploring the geology of the mountains and prairies of Alberta. And because this book addresses geological stops within and adjacent to both Calgary and Edmonton (which between the two cities accounts for $60 \%$ of the population of Alberta), it is a book that can be left in the car for whenever you have the opportunity or desire to get out for a short, informative stroll. Finally, it is such a beautiful book that, left on the coffee table, no one can resist picking it up and having a look. Indeed, there is so much to enjoy about this book that it would be a lovely gift even for someone who is never likely to set foot in Alberta.

But it could be better. In terms of outreach, this is an excellent guidebook. And taken together with his previous effort, Rocks, Ridges and Rivers, it can be argued that between these two guidebooks, no one has done more than Dale Leckie in terms of geological outreach and public Earth Science education over the past 4 years. So, my comments and criticisms offered here are provided in the hope that Dale is not finished publishing guidebooks and that his next effort might be even better. There are errors but they are few and far between (mislocating

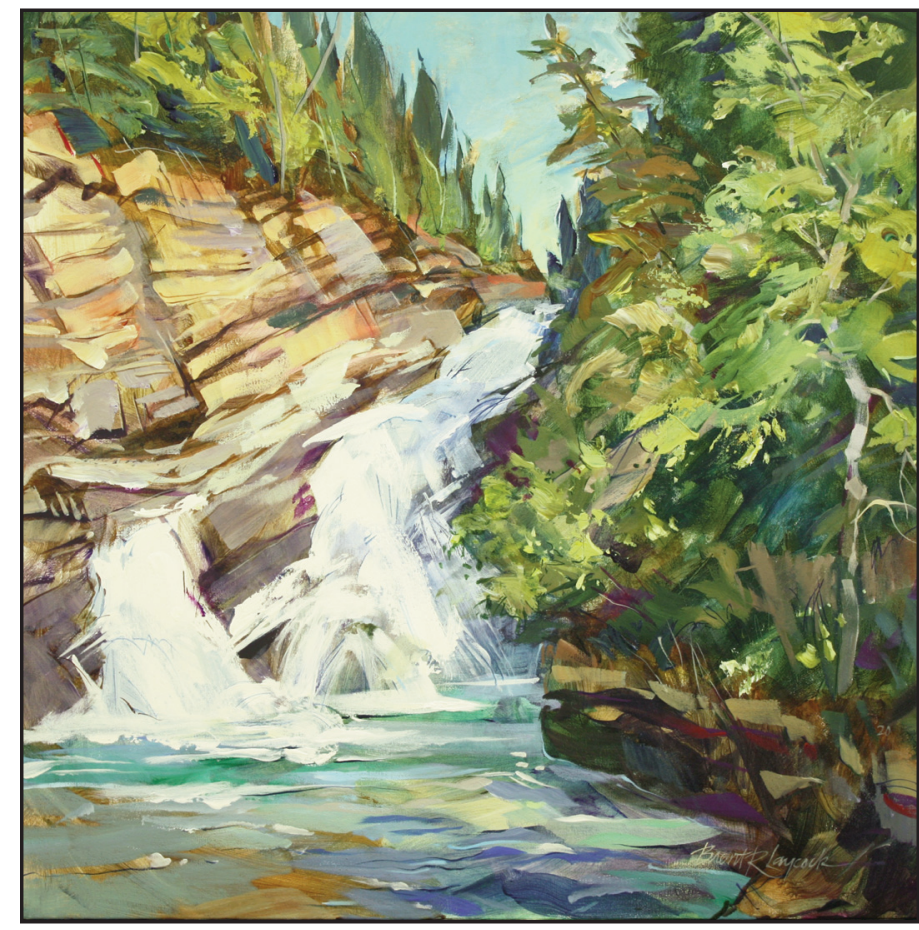

Painting of Cameron Falls descending over Precambrian strata of the Purcell Supergroup in Waterton Park, Alberta. Artist - Brent R. Laycock, Morning Sun on Cameron Falls, acrylic, 2020; used with permission.

Mt Kidd on the map on page 132 being the most notable that I found). The quality of the editing is quite good. No, the two main problems, as minor as they are, can be described as 1) unnecessary confusion, and 2) missed opportunities.

Unnecessary Confusion - The geological stops are organized into "seven subregions", and the subregions are described sequentially. Each starts with a list of the stops within that subregion accompanied by a map showing all the stops. The stops are numbered, and a list is provided showing the page on which the detailed stop description is provided. In addition, the introduction to each subregion features a numbered list describing the main attraction at each location. EXCEPT that the numbers of these short descriptions don't match the numbers on the map. For example, the Southern Alberta subregion includes 16 stops, whereas there are 19 entries in the numbered list of attractions. The map and the attraction list correspond up to number 6 , but then diverge with a couple of attractions described that are not listed as stops. Attractions 10 through 13 correspond to stops 8 through 11 . Attractions 14 and 15 correspond to stop 12 . ... why??

And the subregion designations are at best difficult to understand. Subregion 1 - Southern Alberta, works best. It is an E-W transect consisting of 16 stops that extend from the Crowsnest Pass - Waterton Park region in the west to Cypress Hills in the east. Travelling from west to east we get to experience the wonders of the Rocky Mountains, their foothills, and the Prairies that extend out in front of them. Great stuff, and very logical. And subregion 2, Calgary - Kananaskis, makes sense in that a great many users of this guidebook undoubtedly will be Calgarians. But the organization of the subsequent 


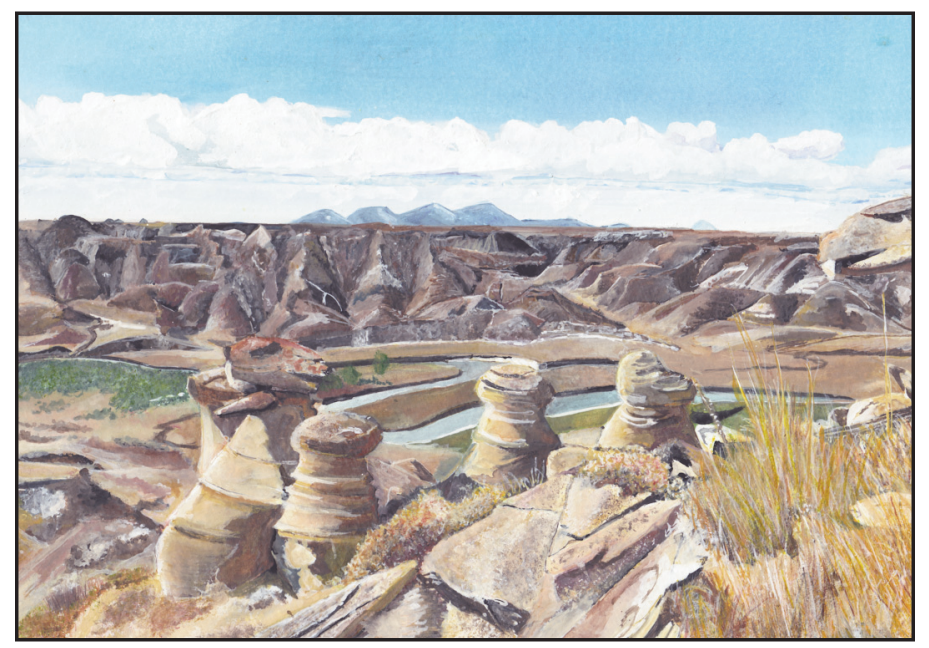

Painting of the Milk River Canyon incised into Upper Cretaceous foreland basin strata of the Western Canadian Sedimentary Basin giving rise to the distinct erosional 'hoodoos'. Artist - L.C. Cariou, Milk River Canyon Hoodoos, watercolour, 2019; used with permission.

subregions defies explanation. Subregion 3 - A Dinosaur Road Trip - consists of a series of 6 stops along the Red Deer River valley, but for some reason, Dinosaur Provincial Park, which lies just downstream along the Red Deer River from subregion 3 , is broken out as its own subregion despite it having only a single described stop (admittedly there are 5 sub-stops, but then why were these not listed as individual stops?). Even stranger, Dinosaur Provincial Park is included in the list of attractions provided for subregion 3. The logic behind subregions 5, 6 and 7 is equally difficult to figure out, which I am not going to belabour. I do, however, want to comment on the Buffalo Head Hills stop in subregion 7 - Checking out the North. I had to read this stop description several times before I understood that there is no stop in the Buffalo Head Hills. Instead, what the reader is asked to do is to stand at the Sagiwata Lookout in the town of Peace River (which happens to be stop 2 of subregion 7, but that isn't mentioned in the description of the Buffalo Head Hills stop) and look $130 \mathrm{~km}$ to the northeast. One hundred and thirty kilometres. I have never been to the Sagiwata Lookout, but I very much doubt that you can see the Buffalo Head Hills from there. This then isn't really a stop at all. It would make more sense to pick a viewpoint in Calgary as a 'stop' in the Rocky Mountains which lie $80 \mathrm{~km}$ to the west. At least you can see the Rockies from Calgary. So, if you happen to find yourself at Sagiwata Lookout someday and you see some very confused looking people, you can probably guess at the source of their confusion.

Missed Opportunities - Earth Science outreach involves informing the public about what we know and don't know about Earth history. What we don't know is just as important as, and can be very much more inspiring than, what we know. No one ever became a geologist or chemist or biologist because everything in those fields had already been figured out. No, people choose to become scientists because they are motivated to explain what hasn't yet been explained, to find answers to outstanding questions, to expand our field of knowledge. From that perspective Scenic Alberta too often depicts our current state of knowledge as being more thorough and detailed than it really is. I provide a couple of examples from the introductory 'Setting the Stage' section. The mountains of Waterton Park owe their existence to the Lewis thrust sheet, which consists of a thick section of the Precambrian Purcell Supergroup emplaced to the east over Cretaceous strata. The amount of slip across the Lewis thrust is difficult to constrain in part because, unlike most thrust faults, the hangingwall strata (Purcell Supergroup) is nowhere to be found in the fault's immediate footwall. Most estimates of the maximum amount of slip across the Lewis thrust are around 80 to $90 \mathrm{~km}$. However, in the Setting the Stage section (and in several other places in the guidebook) the Purcell Supergroup is said to have moved "at about $6 \mathrm{~cm}$ a year for about 23 million years" during thrust emplacement. There are two problems with this statement: 1 - it implies a detailed knowledge of geological rates and time spans that is not supported by data, and 2 - these numbers are demonstrably wrong. A rate of translation of $5 \mathrm{~cm} /$ a for 20 million years yields a total slip of $1000 \mathrm{~km}$. Ironically, I am one of the few people studying Cordilleran geology who would find the suggestion of there having been $>1000 \mathrm{~km}$ of slip across the Lewis thrust as being interesting as opposed to absurd. The real point here is that we simply don't know the specific rates of translation, we don't know the time span over which slip occurred across the Lewis thrust, and we don't know how much slip has occurred across the fault. So why portray our state of knowledge as being so detailed? Similarly, the Crowsnest Volcanics are said to have originated " $92 \mathrm{~km}$ " to the southwest before being transported eastward during thrust belt formation. While this estimate of the distance the Crowsnest Volcanics were translated eastward is reasonable, there is no justification for such a specific number. The Fernie 'basin', which lies just west of the Crowsnest Volcanics has been referred to as "a black hole of thrust faults" (I think Kevin Root was responsible for that quote) and there are significant disagreements over how to palinspastically unravel the Fernie - Crowsnest region. Not only that, but there are paleomagnetic data from the Crowsnest Volcanics that can be interpreted as suggesting that these rocks were deposited more than an order of magnitude farther away from their current location relative to cratonic North America. Providing people with the impression that we have an incredibly detailed understanding of geological processes that took place tens and hundreds of millions of years ago is a missed opportunity.

The other missed opportunity pertains to the use of maps. Geological maps are what make the Earth Sciences unique. They are not strictly data or exclusively interpretation, neither fish n'or fowl. And they are the basis for most all of the fascinating geological stories wedged into this book. And yet geological maps figure sparsely if at all in the stop descriptions. The Waterton Park stop descriptions are provided without a single map showing the trace of the Lewis thrust. And the Waterton Park stops, as well as the Police Outpost Provincial Park and Crowsnest Mountain stops are all about the Lewis thrust sheet. A decent geology map showing the Lewis thrust is subsequently provided (in reference to the Pincher Creek Viewpoint stop), more than 60 pages after the last page con- 
cerning Waterton Park. But even then, the map fails to depict Crowsnest Mountain (a klippe of the Lewis thrust) despite showing the geology of Crowsnest Pass. And because the figures are not numbered or even mentioned in the accompanying text there is no way for a family out using the guidebook to explore Waterton Park to know that there is a useful map of the Lewis thrust sheet to be found on page 131.

Another frustrating lack of map support pertains to the Foothills Erratic Train (FET), a linear train of boulders of Cambrian quartzite that extend from near Hinton in the north, south all the way to and beyond the $49^{\text {th }}$ parallel. The boulder train marks the line of confluence between the Laurentide ice sheet to the east and the Cordilleran ice sheet to the west and is attributed to a landslide from the flanks of Mt Edith Cavell that covered the adjacent Cordilleran glacier with quartzite debris. The FET is featured and described and explained on pages 129, 133, 140 and 141 (which features a breakout sidebar on the topic). All of this without a map showing the boulder train, or Mt Edith Cavell, or the extent of the Cordilleran and Laurentide ice sheets. But we are finally provided with such a map on pages 156-157 where the Okotoks Big Rock, the most famous of the FET's boulders, is described. Unfortunately, given the way people use field guides (only looking at the pages pertinent to their current stop) and the lack of numbered figures, it means that only those reviewing this guide or those visiting the Okotoks Big Rock are going to see the map that beautifully explains the origins of the FET.

These criticisms in no way diminish what Dale Leckie has accomplished. He has more than adequately achieved his goal of sharing his obvious "curiosity for natural history". Scenic Alberta is a beautiful guidebook that seamlessly combines art and science in a highly successful effort to explain the geological processes and deep time involved in the development some of Alberta's most picturesque landscapes. We in the Earth Science community owe a huge debt of gratitude to Dale because, as I wrote in a 2011 Geoscience Canada article (Johnston 2011), "a public ignorant of the basic workings of the Earth and of the depth of Earth history, will never be able to imagine the substantial challenge that humanity currently faces."

\section{REFERENCES}

Johnston, S.T., 2011, The Earth Sciences: Our legacy and our future: Geoscience Canada, v. 38, p. 145-148, https://id.erudit.org/iderudit/geocan38_4pre01. 